\title{
ENVIRONMENTAL EFFICIENCY OF INDUSTRIAL sciendo SYMBIOSIS - LCA CASE STUDY FOR GYPSUM EXCHANGE
}

doi:10.2478/mape-2018-0100

Date of submission of the article to the Editor: 03/2018 Date of acceptance of the article by the Editor: 06/2018
MAPE 2018, volume 1, issue 1, pp. 793-800

\author{
Dr Andrzej Marcinkowski \\ Lodz University of Technology, Poland
}

\begin{abstract}
A review of the available literature concerning environmental impact assessment for industrial symbiosis has been carried out. The authors have recommended the use of life cycle assessment method for this purpose. It was stated that so far few studies presenting LCA results of industrial symbiosis have been published. Among the factors which contribute to the success of symbiotic exchange, the close location of collaborating companies has been often mentioned.

This paper presents LCA results concerning the environmental impact of symbiotic gypsum transmission. Concepts of relative distance and critical distance for the case of industrial symbiosis were proposed and defined. Significant difference between critical distance obtained for particular endpoints were observed (3.5$564 \mathrm{~km}$ ). Application of Life Cycle Sustainability Triangle enabled the estimation of critical distance taking into account various impact categories. A sensitivity analysis indicated the relationship between critical distance and the means of transport which reflected the effect of scale. The critical distance determined for heavy trucks was $3.2-3.9$ times longer than in case of lighter vehicles.
\end{abstract}

Keywords: industrial symbiosis, life cycle assessment, gypsum

\section{INTRODUCTION}

The business model of industrial symbiosis, defined as collaboration between companies whereby the wastes or by-products of one become a resource for another, has been identified as a key factor enabling the move towards a circular economy. The development of such industrial eco-systems is one of the most promising and available ways to embody the concept of sustainable development (EEA, 2016; Singh et al., 2007).

The most important idea of industrial symbiosis is transfer of by-products or waste flows generated by one company to another one in order to use them for production purposes instead of natural resources. Industrial symbiosis involves cooperation aimed at achieving a competitive advantage by taking advantage of the synergy effect resulting from the close proximity of industrial plants of collaborating companies (Chertow, 2000). Close distance between enterprises is a very important factor for the success of symbiotic connections since it has a direct impact on transport costs of by-products. In case of too long distance, transport cost could exceed the economic value of waste flow being exchanged and cooperation would not be profitable (Mauthoor, 2017; Lowe, 1997).

As the symbiotic initiatives are supposed to increase environmental performance, apart from financial profitability, environmental benefits and losses should be taken into account. The use of waste as a raw material certainly brings environmental benefits. However, the required transport causes an additional environmental burden. If the distance between the cooperating companies were too long, the environmental balance would become negative and the symbiotic connection between them would lose its environmental justification.

The environmental balance of a single symbiotic relationship is determined by a number components, such as: 
- no need for conventional waste treatment;

- the use of waste material or energy;

- the need to transport the waste to the place of use;

- the necessity of preliminary processing of waste so that it can be used as a raw material;

- the need to modify the technological process for using the acquired waste flow.

Only two first represent a positive influence on the environment.

\section{METHODOLOGY OF RESEARCH}

It is not easy to determine the environmental balance. An appropriate method should be chosen which takes into account many different variables to determine the total environmental impact (benefit and burden). Since the industrial symbiosis consists in a cooperation between companies, the environmental balance assessment should not be limited to impacts of one separate industrial plant. The method meeting the above conditions is life cycle assessment (LCA). Moreover, LCA is recommended for environmental impact assessment in case of industrial symbiosis (Singh et al., 2007; Sokka et al., 2008; Mattila et al., 2010; Sokka et al., 2010; Sokka et al., 2011). The authors expressed the need to use a full life cycle assessment to analyze industrial ecosystems. However, so far only a few studies have applied the life cycle assessment to assess the benefits of industrial symbiosis (Daddi et al., 2017). The juxtaposition and classification of methodologies of such research have been presented by (Mattila et al., 2012).

Life cycle assessment consists in a comprehensive analysis of the environmental impact associated with sequential phases of the analyzed object's life cycle such as resources extraction, raw material processing, manufacturing, transport, use, disposal. The basic principles of this method are standardized. Requirements for the particular LCA procedures are included in international standards for environmental management (ISO 14040; ISO 14044).

The life cycle assessment of a single symbiotic connection demands to determine environmental impact separately for each component of the environmental balance. Thanks to this, the comparison of positive and negative part of the impact is possible so that the final conclusion can be drawn whether or not the analyzed symbiotic initiative is environmentally justified.

As it was mentioned before, one of the component of the balance, namely environmental impact of transport, is crucial for the final result. Usually in case of analysis of existing symbiotic networks the transportation distance between companies is known and results in a fixed negative impact. To obtain more general conclusion of this research, the aim of this paper is to determine the maximum distance for a given waste flow exchange at which the symbiotic initiative is justified from environmental point of view. In other words, the research presented here is focused on determination of the critical distance between industrial plants that results in an environmental break-even point.

One of typical by-product of inter-company transfers within industrial symbiosis is gypsum. This is due to the fact that often a central role in the symbiotic network is played by a coal-fired power plant. The combustion of coal causes the formation of significant amounts of sulfur dioxide, which is converted into gypsum during the desulfurization process. Gypsum is a widely used raw material in the construction industry. Companies from this sector often collect power plant' by-product.

Taking into account the recommendations of the authors of the previous publications in this field, the research will be carried out using life cycle assessment method. In this way, this article will enrich the rather poor literature presenting LCA results concerning industrial ecosystems.

Since gypsum produced in a power plant does not require any extra preparation process, the balance of environmental benefits and losses of the symbiotic connection involves: 
- the benefit of the use of gypsum;

- the benefit of no need for waste landfill;

- the benefit of no need for transport waste to landfill;

- the loss of the need to transport the waste to the place of use.

Transport contributes both in positive and negative environmental impact.

In order to eliminate an dependence of the distance between power plant and heap or landfill (place where gypsum is dumped) on results, it has been assumed that regardless of destination (collaborating company or dump place) the transport mean is the same. Thanks to this assumption a research model structure is simplified as illustrated by Fig. 1 .

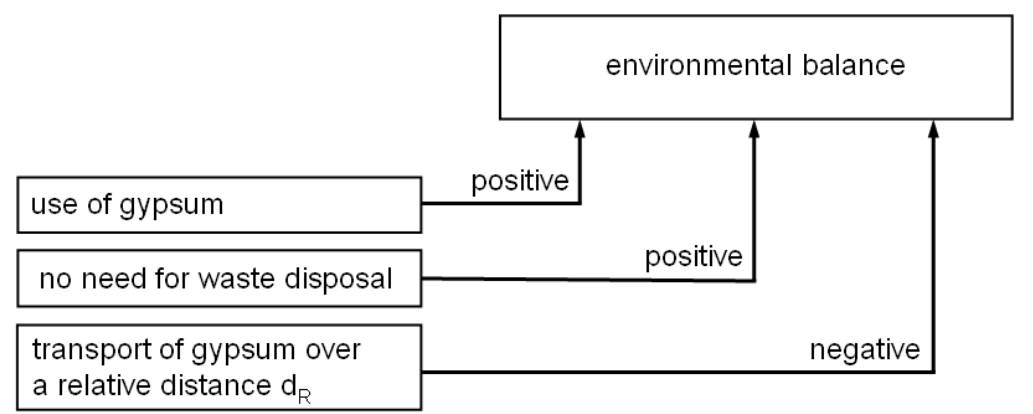

Fig. 1. Model structure for environmental impact analysis of gypsum exchange

The relative distance $d_{R}$ can be expressed by equation (1).

$$
d_{R}=d_{S}-d_{D}
$$

where:

$d_{S}$ - distance between power plant and the company which uses by-product;

$d_{D}$ - distance between power plant and dump place.

The above model assumptions result in a simple conclusion: if the distance to the landfill place is greater than the distance to the collaborating company $\left(d_{D}>d_{S}\right)$, the symbiotic initiative is always profitable from environmental perspective. Otherwise, the total environmental profitability depends on the relations between positive components of balance and environmental impact of transport.

The research model does not have to assume the amount of gypsum that is used, as all three balance components are proportionate to it. The unit environmental impact is independent of this amount. However, in order to obtain specific numerical results 10,000 tons of gypsum was assumed as functional unit.

The critical distance will be determined from the perspective of three endpoint impact categories. Their indicators are expressed in independent units:

- ecosystem quality: PDF $\cdot \mathrm{m}^{2} \cdot$ year, (potentially disappeared fraction);

- human health: DALY, (disability adjusted life-years);

- resources: MJ of surplus energy.

Subsequent LCA procedures (inventory analysis, classification, characterisation, normalisation) will be carried out using the Eco-indicator 99 method by means of SimaPro software. The research carried out covered the analysis of various scenarios that differed in particular parameters. European conditions were assumed.

\section{RESULTS}

Fig. 2 depicts environmental impact of symbiotic gypsum exchange over a sample distance of $20 \mathrm{~km}$ in terms of relative normalisation indicators. In case of category of ecosystem quality the results indicate negative environmental impact (the bars are situated mostly above the zero axis). In both other categories, human heath and resources, a positive environmental 
impact is observed (most of bars are situated below zero). The presented results lead to the following conclusions:

- from the point of view of human heath and resources, the critical distance has not been exceeded (the critical distance is longer than $20 \mathrm{~km}$ );

- from ecosystem quality perspective, the critical distance is less than $20 \mathrm{~km}$.

This conclusion suggests to perform separate analyses for individual categories.

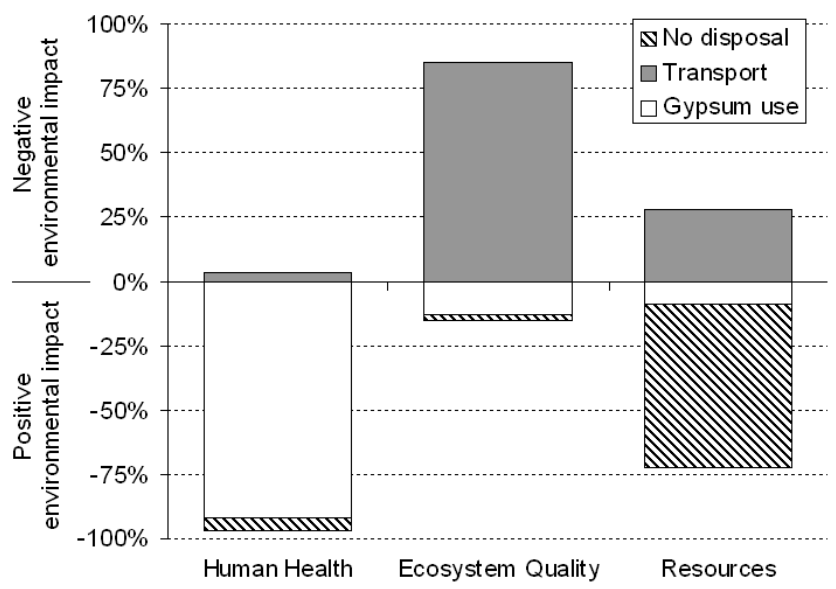

Fig. 2. Indicators for symbiotic gypsum exchange over a distance of $20 \mathrm{~km}$

By additional analysis and interpolation critical distances were determined separately for different endpoints.

Fig. 3. presents process network for resources category for the scenario of symbiotic initiative involving gypsum transport over a critical distance $d_{c r R}$ of $51.4 \mathrm{~km}$. Positive (light arrows) and negative (dark arrows) environmental impacts are balanced indicating that the critical distance has been obtained. An environmental benefit is predominated by no necessity of gypsum disposal ( $87 \%$ of total environmental benefit). Environmental burden results only from transport. Main components of it are:

- operation of transport mean ( $81 \%$, including fuel production $67 \%)$;

- road construction $(9.2 \%)$,

- road maintenance $(0.4 \%)$,

- lorry manufacturing (3.0\%),

- lorry maintenance (3.6\%).

The assumption has been made that the vehicle and road also have other functions and are only partially used to gypsum transport. Thus, only a part of environmental impact of the vehicle and road has been taken into account, proportionate to the relative contribution of symbiosis to their total life cycle impact.

The process network for human health category for the scenario of symbiotic initiative involving gypsum transport over the critical distance $\mathrm{d}_{\mathrm{crHH}}$ of $564 \mathrm{~km}$ is depicted in Fig. 4. An environmental benefit is predominated by gypsum utilization $(89 \%$ of total environmental benefit). The main components of environmental loss resulting from transport are:

- operation of the vehicle (83\%, including fuel production $11 \%)$;

- lorry manufacturing $(6.4 \%)$,

- road construction (7.6\%),

- lorry maintenance $(1.9 \%)$

- road maintenance $(1.1 \%)$.

A difference between particular components contribution determined for both endpoints (resources and human health) can be observed. The most pronounced difference is visible in environmental benefit structure. From resources depletion's point of view, the positive impact 
results from avoided gypsum disposal, while from human health perspective gypsum use predominates. A clear difference is also observed in impact structure of vehicle operation.

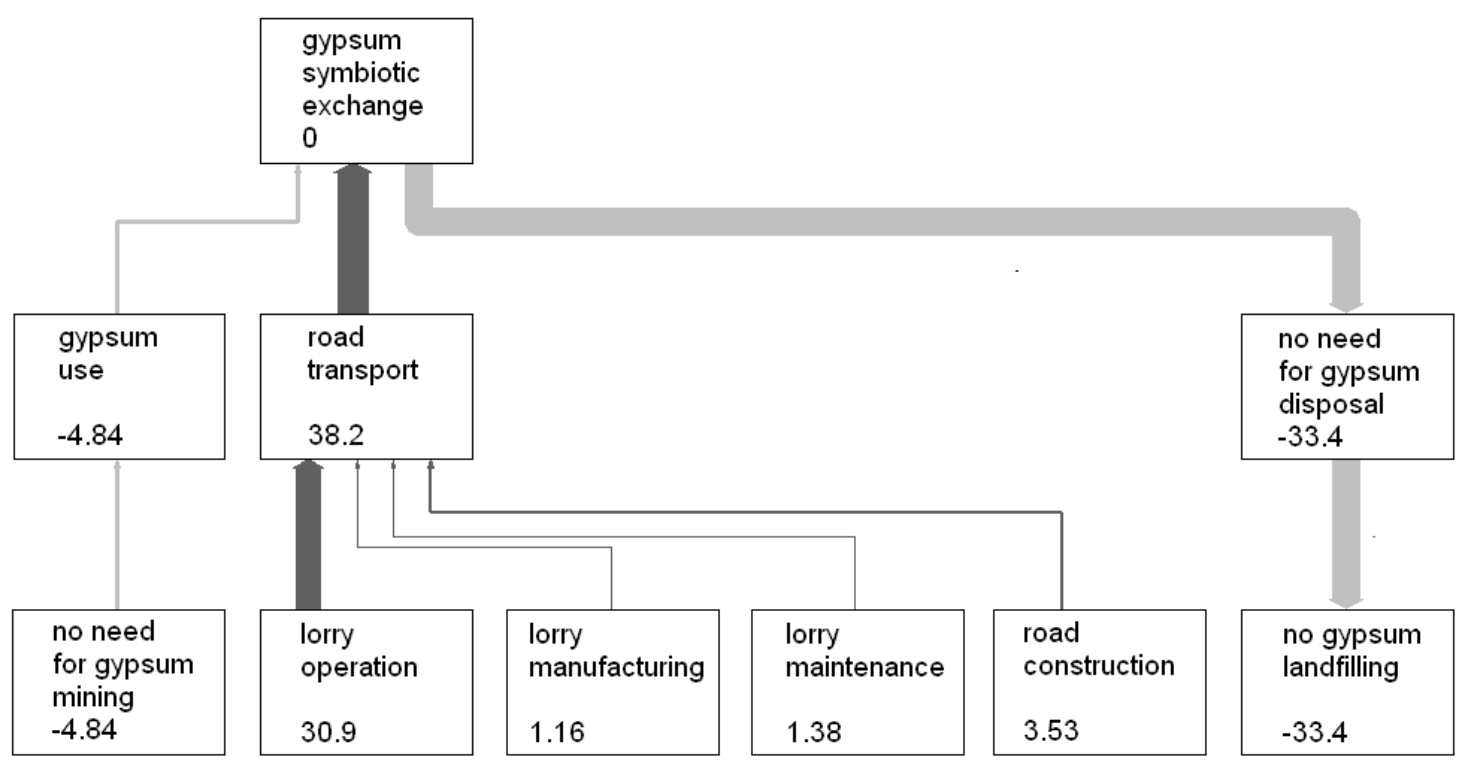

Fig. 3. Process network for resources category for symbiotic gypsum exchange over a critical distance $d_{c r R}$

From resources depletion's point of view, the most essential contribution was connected with fuel consumption $(83 \%)$, whereas from human health perspective the contribution of fuel use is far less important (13\%). Exhaust fume emission impact predominates in this case.

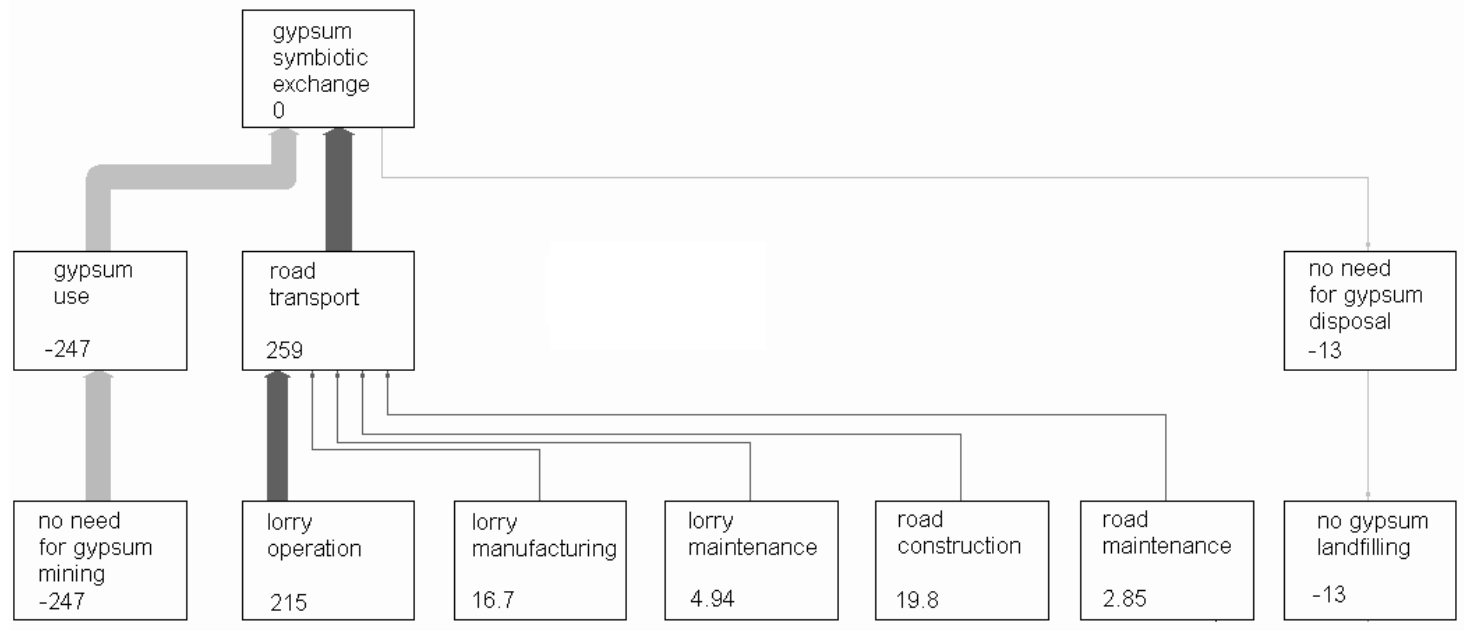

Fig. 4. Process network for human health category for symbiotic gypsum exchange over a critical distance $d_{c r H H}$

When it comes to category of ecosystem quality, a comparable short critical distance is expected $(<20 \mathrm{~km})$ due to the initial assessment. By means of results interpolation critical distance $d_{\text {crEQ }}$ has been determined on the level of $3.5 \mathrm{~km}$. Fig. 5. presents process network for the scenario of symbiotic connection involving gypsum transport over the critical distance for ecosystem quality category. As in the case of the human health endpoint, by-product use predominates within environmental benefits ( $84 \%$ of total benefit). The most vital component 
of environmental load resulting from transport is vehicle operation (78\%) where fume emission impact predominates (also like in the case of human health category).

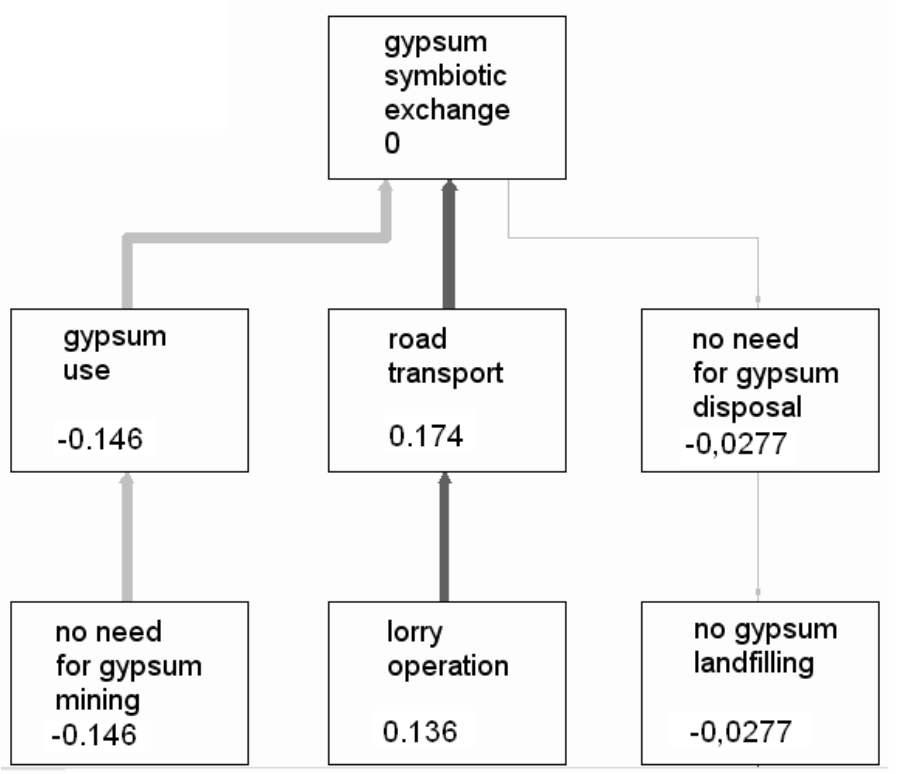

Fig. 5. Process network for ecosystem quality category for symbiotic gypsum exchange over a

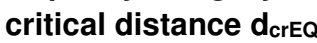

\section{DISCUSSION}

Considering environmental impact of symbiotic gypsum exchange from different endpoint perspective, a very wide range of the critical distance has been obtained (3.5-564 km). Since it is very difficult to compare the environmental impact associated with different impact categories, avoiding an arbitrary procedure of weighting, it could be assumed that the ultimate critical distance taking into account all the results is the smallest value $(3.5 \mathrm{~km}$ determined for ecosystem quality endpoint). However, due to significant discrepancies between the figures, comprising more than two orders of magnitude, as well as relatively low ecosystem quality indicators, the assumption like this would be controversial. From the perspective of other categories significant environmental benefits were reported for much longer distances. Setting the ultimate critical distance at $3.5 \mathrm{~km}$ would mean no recommendation for gypsum transmission over longer distance and ignoring environmental benefits associated with human health and resources. In order to solve the problem, a method applying the Life Cycle Sustainability Triangle (LCST) was used.

Fig. 6a depicts LCST for environmental impact comparison of the symbiotic gypsum transmission over the distance of $100 \mathrm{~km}$ with the reference scenario assuming no symbiotic exchange. The grey colour of the triangle indicates an area where the total environmental impact of industrial symbiosis is more positive than that of the reference scenario. Despite the distance is far longer than $d_{\mathrm{crEQ}}$, grey colour predominates on the graph. Symbiotic initiative is recommended for most weighting sets. The reference scenario can be recommended only for the very low weight coefficients assigned to the human health endpoint. Using a set of weighting coefficients where this endpoint would have several times lower weight than others would be very controversial. Setting the ultimate critical distance of $100 \mathrm{~km}$ (or less) would mean ignoring environmental benefits associated human health category. It can be concluded that the critical distance, taking into account all categories, is longer. 

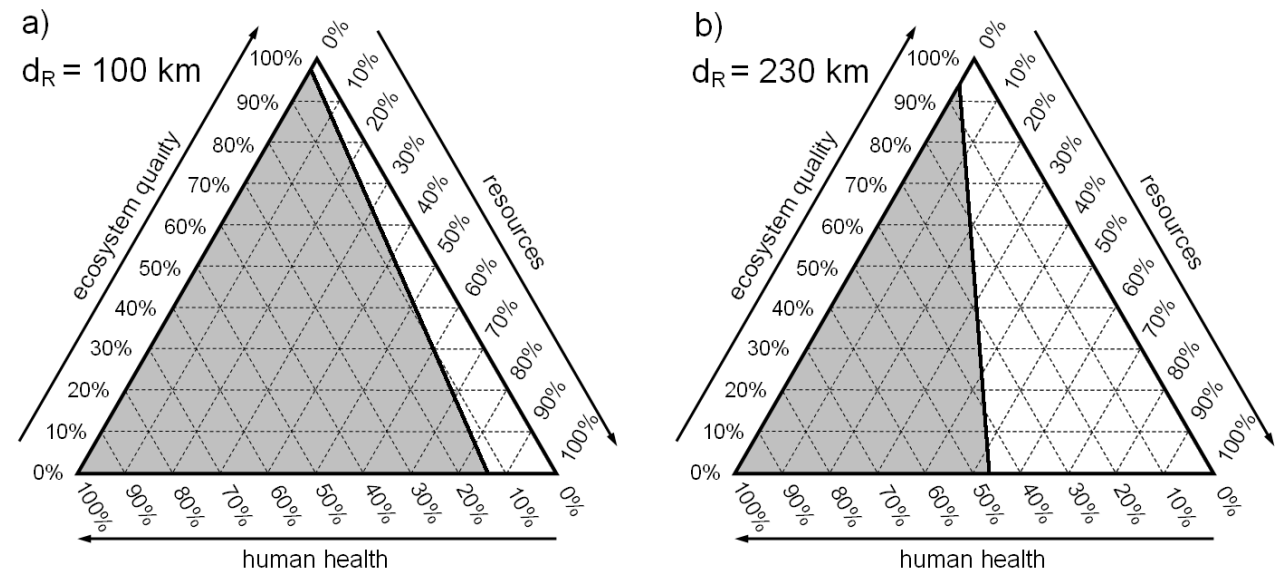

Fig. 6. Life Cycle Sustainability Triangle for symbiotic gypsum exchange over a relative distance of $100 \mathrm{~km}$ and $230 \mathrm{~km}$

By additional analysis and interpolation the critical distance was determined for which half of the LCST area indicates recommendation for symbiosis initiative (grey area), and the second half suggests that no symbiotic cooperation should be undertaken (white area). The balance observed has been obtained for the relative distance of $230 \mathrm{~km}$. The ultimate critical distance taking into account environmental impact within all the categories can be assumed to be around this figure. It can be stated that for $d_{R}>230 \mathrm{~km}$ industrial symbiosis involving gypsum transmission is not justified environmentally.

Important parts of LCA study are uncertainty and sensitivity analyses. According to initial assumptions, accuracy of crucial parameters of the research did not have any significant impact on results. Amount of by-product transmitted was proportionate to all environmental balance components. The distance from power plant to gypsum disposal place was excluded from the model. The distance between symbiotic partners was supposed to be determined. When it comes to sensitivity, various types of road transport were analyzed to compare their impact on results. A dependence of vehicle size on the critical distance was observed. The results presented above assumed average trucks with total permissible mass from the range of 3.5-28 $t$ as a transport mean. Fig. 7 depicts a relationship between vehicle size and critical distance. In case of heavy trucks ( $>16 \mathrm{t}$ ) the critical distance is significantly longer than in case of light ones $(<7.5 \mathrm{t})$. This results from environmental impact per transport unit $(\mathrm{t} \cdot \mathrm{km})$. In order to transport the same amount of by-product, a longer distance must be covered by lighter vehicle that results in greater environmental impact.

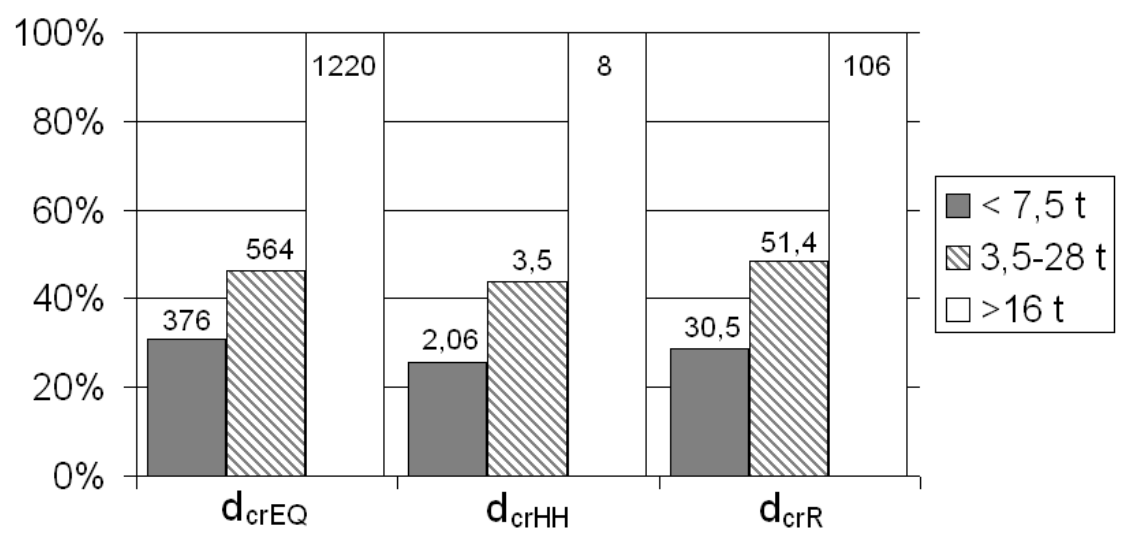

Fig. 7. The dependence between vehicle size and critical distance 


\section{CONCLUSION}

The results presented in this paper confirm that the life cycle assessment method can be useful tool for environmental impact assessment of symbiotic initiatives. The concepts of relative distance and critical distance seem to be helpful to reflect the environmental potential of industrial symbiosis.

Substantial differences between the results obtained in case of individual endpoints were observed. They results from different characteristics of environmental impact within human health, ecosystem quality and resources categories. Without the Life Cycle Sustainability Triangle method application, it would be difficult to draw consistent conclusion in terms of one critical distance.

The results reflected also the effect of scale. Depending on particular impact category, the critical distance determined for heavy trucks, was 3.2-3.9 times longer than in case of lighter vehicles.

\section{REFERENCES}

Chertow, M.R. (2000). "Uncovering" Industrial Symbiosis. Journal of Industrial Ecology, 11(1), pp. 11-30.

Daddi, T., Nucci, B., Iraldo, F. (2017). Using Life Cycle Assessment (LCA) to measure the environmental benefits of industrial symbiosis in an industrial cluster of SMEs. Journal of Cleaner Production 147, pp. 157-164.

European Environment Agency, (2016). Circular economy in Europe. Developing the knowledge base, EEA Report No. 2/2016, Publications Office of the European Union, Luxembourg.

International Organization for Standardization, (2006). ISO 14040 Environmental management - Life cycle assessment - Principles and framework.

International Organization for Standardization, (2006). ISO 14044 Environmental management - Life cycle assessment - Requirements and guidelines.

Lowe, E.A. (1997). Creating by-product resource exchanges: strategies for eco-industrial parks. Journal of Cleaner Production, 5(1-2), pp. 57-65.

Mattila, T., Pakarinen, S., Sokka, L. (2010). Quantifying the Total Environmental Impacts of an Industrial Symbiosis A Comparison of Process-, Hybrid and Input-Output Life Cycle Assessment. Environmental Science and Technology, 44(11), pp. 4309-4314.

Mattila, T., Lehtoranta, S., Sokka, L., Melanen, M., Nissinen, A. (2012). Methodological Aspects of Applying Life Cycle Assessment to Industrial Symbioses. Journal of Industrial Ecology, 16(1), pp. 51-60.

Mauthoor, S. (2017). Uncovering industrial symbiosis potentials in a small island developing state: The case study of Mauritius. Journal of Cleaner Production, 147, pp. 506-513.

Singh, A., Loua, H., Yawsa, C., Hopper, J., Pike, R. (2007). Environmental impact assessment of different design schemes of an industrial ecosystem. Resources, Conservation and Recycling 51, pp. 294313.

Sokka, L., Melanen, M., Nissinen, A. (2008). How can the sustainability of industrial symbioses be measured? Progress in Industrial Ecology An International Journal, 5(5/6), pp. 518-535.

Sokka, L., Lehtoranta, S., Nissinen, A., Melanenet, M. (2010). Analyzing the Environmental Benefits of Industrial Symbiosis Life Cycle Assessment Applied to a Finnish Forest Industry Complex. Journal of Industrial Ecology, 15(1), pp. 137-155.

Sokka, L., Pakarinen, S., Melanen M. (2011). Industrial symbiosis contributing to more sustainable energy use - an example from the forest industry in Kymenlaakso, Finland. Journal of Cleaner Production 19, pp. 285-293. 